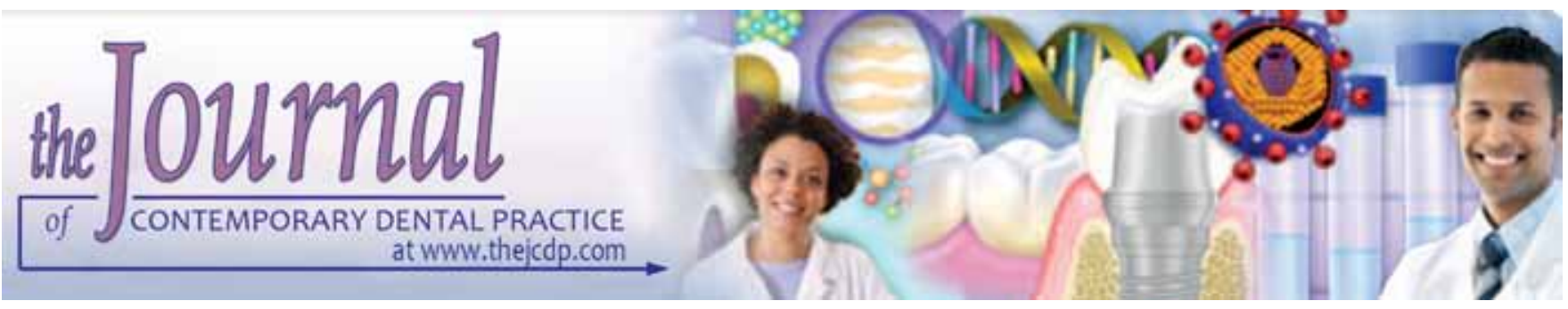

\title{
Effect of the Association between Citric Acid and EDTA on Root Surface Etching
}

Fabio Renato Manzolli Leite, Gustavo Giacomelli Nascimento, Elza Regina Manzolli Leite Amauri Antiquera Leite, José Eduardo Cezar Sampaio

\section{ABSTRACT}

Objective: This study aims to compare the clot stabilization on root surfaces conditioned with citric acid and ethylenediaminetetraacetic acid (EDTA).

Materials and methods: Scaled root samples $(n=100)$ were set in five groups: group I-control group (saline solution); group II (24\% EDTA); group III (25\% citric acid); group IV (EDTA + citric acid); group V (citric acid + EDTA). Fifty samples were assessed using the root surface modification index (RSMI). The other 50 received a blood drop after conditioning. Clot formation was assessed using blood elements adhesion index (BEAI). A blind examiner evaluated photomicrographs. Statistical analysis considered $p<0.05$.

Results: Groups-III and G-V attained the best results for RSMI and BEAI in comparison to control. The worst results for clot stabilization were seen in group-II. EDTA employment before citric acid (group-IV) reduced clot formation in comparison to citric acid use alone (group-III).

Conclusion: Root conditioning with citric acid alone and before EDTA had the best results for smear layer removal and clot stabilization. EDTA inhibited clot stabilization on root surface and must have a residual activity once it has diminished clot adhesion to root even after citric acid conditioning. Thus, EDTA can be used to neutralize citric acid effects on periodontal cells without affecting clot stabilization.

Clinical significance: To demonstrate that citric acid use on root surfaces previously affected by periodontal disease may favor clot stabilization and may have a beneficial effect on surgical outcomes. Also, EDTA can be used to neutralize citric acid effects on periodontal cells.

Keywords: Blood, Smear layer, Edetic acid, Citric acid.

How to cite this article: Leite FRM, Nascimento GG, Leite ERM, Leite AA, Sampaio JEC. Effect of the Association between Citric Acid and EDTA on Root Surface Etching. J Contemp Dent Pract 2013;14(5):796-800.

Source of support: This study was supported by FAPESP (Fundação de Amparo à Pesquisa de São Paulo), grant number 03/04252-2 and 03/04754-8, São Paulo state, Brazil.

Conflict of interest: None declared

\section{INTRODUCTION}

The objective of the periodontal therapy is to repair the support tissues compromised by periodontal disease, e.g. alveolar bone, periodontal ligament and cementum. One essential condition for periodontal regeneration is the creation of a biocompatible surface without bacterial cells and maintenance of a stable clot on root surface, ideal for migration and cell proliferation. ${ }^{1}$

The regeneration is more predictable on surfaces biologically acceptable obtained by mechanical scaling and planing. However, root scaling alone generates a contemned smear layer with bacterial residues, ${ }^{2,3}$ thus it is necessary to use substances to remove this layer.

Citric acid, tetracycline hydrochloride (TTC) and ethylenediaminetetraacetic acid (EDTA) are the most used substances for smear layer removal and collagen fibers exposure. ${ }^{4,5}$ Some studies indicate that this demineralized tissue can enhance connective tissue attachment to root surface and blood element adsorption and adhesion which is an important factor for the outcomes of wound healing. ${ }^{6}$

The aim of this study was to compare the influence of root conditioning with the association between citric acid and EDTA on blood element adsorption and adhesion to root surfaces. Moreover, the evaluation of the effect of EDTA use as a neutralizing agent after citric acid use.

\section{MATERIALS AND METHODS}

This study was approved by the Research Ethics Committee of the School of Dentistry at Araraquara, São Paulo State University - UNESP (protocol 10/04). Fifty teeth were obtained at the undergraduation clinics. Inclusion criteria for teeth were advanced periodontal breakdown (attachment loss in more than $50 \%$ of root length), caries-free cementoenamel junction (CEJ) and donor must be never smoker due to higher degree of mineralization of teeth of smokers. 
Teeth were stored in tubes (Axygen, Union city, LA, USA) containing filtered water at room temperature. Water was renewed once a week to avoid acidification and tooth decalcification, microorganism growth and sample dehydration.

\section{Sample Preparation}

Two parallel grooves of $0.5 \mathrm{~mm}$ depth were made with a cylindrical bur (KG Sorensen, Barueri, São Paulo, Brazil) under copious irrigation and samples were obtained from the cervical third of the roots. The first groove was positioned horizontally at the CEJ and the second $4 \mathrm{~mm}$ apical in relation to the first. The area between the two grooves was scaled with 50 apicocervical strokes using a sharp \#5-6 Gracey curette (Hu-Friedy, Chicago, IL, USA).

Two samples were produced from each tooth and a total of 100 samples were prepared and stored in the same tubes containing filtered water.

\section{Root Conditioning}

Fifty samples were used to assess root surface modification and the other 50 were fixed into containers using utility wax to maintain their stable during blood application ( $\mathrm{n}=10$ per group). Specimens were divided into five groups containing 20 samples each:

- Group I (control): irrigation with $10 \mathrm{ml}$ of saline solution

- Group II: 24\% EDTA (PrefGel, Biora AB, Malmö, Sweden) application with a soft brush

- Group III: $25 \%$ citric acid solution (Vetec, São Paulo, SP, Brazil) application using a cotton pellet embedded in the solution

- Group IV: application of $24 \%$ EDTA followed by $25 \%$ citric acid

- Group V: application of $25 \%$ citric acid followed by $24 \%$ EDTA.

Samples in the groups II, III, IV and V were conditioned during 3 minutes and solutions were renewed every 30 seconds. ${ }^{1,4}$ After the conditioning procedure samples were washed with $10 \mathrm{ml}$ of saline solution.

\section{Preparation for SEM}

Fifty samples (10 of each group) were prepared for SEM analysis of the conditioned surface. Samples were dehydrated by the critical point method which consisted of immersion in ethanol concentrations of 30, 50, 70, 80, 95 and $100 \%$ for 1 hour each. After the final immersion in the $100 \%$ ethanol concentration, samples were immersed in a $50 \%$ (v/v) solution of $100 \%$ ethanol and hexamethyldisilazane (HMDS) (Sigma, Sigma-Aldrich Inc, St Louis, MO, USA) for 30 minutes and a final immersion in HMDS only for 10 minutes. HMDS allows visualization of the collagen matrix in SEM photomicrographs. Finally, samples were dried for 48 hours in a dehydration jar (Corning, São Paulo, SP, Brazil) and mounted on metallic holders (Senai, São Paulo, SP, Brazil) for sputter coating with $99.99 \%$ pure gold.

\section{Blood Elements Adhesion Evaluation}

The remaining 50 samples received a drop of fresh blood on it and left to rest for 20 minutes to allow clot formation. After this period, samples were washed three times for 5 minutes in PBS (Merck, Darmstadt, Hesse, Germany), under soft agitation (60 rpm) (Mini-Rocker Shaker, Boeco, Hamburg, Germany).

\section{Preparation for SEM}

Samples were fixed in formaldehyde 1\% (Merck, Darmstadt, Hesse, Germany) solution in PBS for 15 minutes and washed three times for 5 minutes in PBS. After this, samples were incubated for 10 minutes in $0.02 \mathrm{M}$ glycine (Merck, Darmstadt, Hesse, Germany) solution in PBS and washed as described earlier. Subsequently, samples were fixed in glutaraldehyde 2.5\% solution (Merck, Darmstadt, Hesse, Germany) in PBS for 30 minutes and washed as described earlier. Then they were dehydrated by immersion in ethanol concentrations of $25,50,75$ and $95 \%$ for 10 minutes each and washed three times for 10 minutes each in $100 \%$ ethanol. The dehydration process was finished in a critical point device (Bal-Tec CPD 030, Miami, FL, USA). Finally, samples were mounted on metallic holders for sputter coating with $99.99 \%$ pure gold. Table 1 illustrates sample distribution on the experimental groups.

\section{SEM Examination}

Photomicrographs were made in a scanning electron microscope (JEOL JSM-T330A, Miaka, Tokyo, Japan) adjusted to $20 \mathrm{kV}$ in the center area of each sample. Samples

\begin{tabular}{lccccc}
\multicolumn{7}{c}{ Table 1: Frequency distribution of scores according to the RSMI } \\
\hline & Control (I) $n(\%)$ & $\begin{array}{c}\text { EDTA (II) } \\
n(\%)\end{array}$ & $\begin{array}{c}\text { Citric acid (III) } \\
n(\%)\end{array}$ & $\begin{array}{c}\text { EDTA + Citric acid (IV) } \\
n(\%)\end{array}$ & $\begin{array}{c}\text { Citric acid + EDTA (V) } \\
n(\%)\end{array}$ \\
\hline Score 1 & 0 & $2(20)$ & $7(70)$ & 0 & 0 \\
Score 2 & $1(10)$ & $8(80)$ & $3(30)$ & $10(100)$ & $1(10)$ \\
Score 3 & $9(90)$ & 0 & 0 & 0 & $9(90)$ \\
\hline Total & 10 & 10 & 10 & 10 & 10 \\
\hline
\end{tabular}


that received blood application were evaluated under 500× and $1,000 \times$ magnifications and all other samples were evaluated under 2,000× magnification. Evaluation was performed by a trained and calibrated examiner who was unaware of the experimental groups.

Root surface modification index (RSMI) ${ }^{1}$ was used to evaluate photomicrographs of samples who received root conditioning procedures only:

- Score 1: Observation of cementum/dentin and exposure of collagen of dental matrix

- Score 2: Observation of cementum/dentin with no exposure of collagen of dental matrix

- Score 3: Presence of smear layer.

Finally, photomicrographs of samples that received blood application were evaluated by the blood elements adhesion index (BEAI) ${ }^{1}$ :

- Score 0: Absence of fibrin network and blood cells.

- Score 1: Scarcely distributed fibrin network and/or blood cells.

- Score 2: Moderate number of blood cells and thin fibrin network with poor interlacing.

- Score 3: Dense fibrin network with rich interlacing and presence of blood cells.

Each photomicrograph was evaluated three times in intervals of at least 7 days. The score attributed to each sample was the most prevalent score in the three evaluations. Good reproducibility was achieved in the use of the indexes Kappa, $\kappa=0.810$ (BEAI) and $\kappa=0.949$ (RSMI).

\section{STATISTICAL ANALYSIS}

Groups were compared on ordinal (RSMI and BEAI) and dichotomous variables by parametric analysis of variance (one-way ANOVA and Tukey tests) using a significance of $p \leq 0.05$. These analyses were performed using the software Graph Pad Instat Software 5.05 (San Diego, CA, USA).

\section{RESULTS}

Results from RSMI showed difference between control group and all other groups $(p=0.0001)$. Nevertheless, group II presented score 1 frequency of $20 \%$ and score 2 of $80 \%$; the group III presented score 1 frequency of $70 \%$ and score 2 of $30 \%$, the best results on RSMI. Less favorable results were observed in the control group and group $\mathrm{V}$ with $10 \%$ of score 2 and $90 \%$ of score 3 . Group IV presented samples with $100 \%$ of score 2 (Table 1 ).

A great variation in morphologic aspects of fibrin network and blood cells amount could be seen. Analyzing the scores of each group separately, almost all samples of groups II, III and V had the same scores, denoting that these treatments are able to provide homogeneous final results. However, in groups I and IV, scores ranged from 0 to 3 with inconsistent results as seen on Table 2.

ANOVA test rejected the hypothesis that all groups have the same performance in clot stabilization $(p<0.0001)$. This way, the variation among groups' medians was significantly greater than expected by chance. Graph 1 summarizes ANOVA and Tukey tests results. EDTA presented the worst results regarding clot organization compared to all groups. The use of citric acid alone or before EDTA increased the clot stabilization potential $(p<0.0001)$. The use of citric acid after EDTA improved clot organization when compared to the use of EDTA alone $(p<0.05)$. Citric acid conditioning improved clot stabilization when compared to control group $(\mathrm{p}<0.0001)$.

\section{DISCUSSION}

The main goal of the periodontal therapy is to promote connective tissue attachment to roots previously exposed to

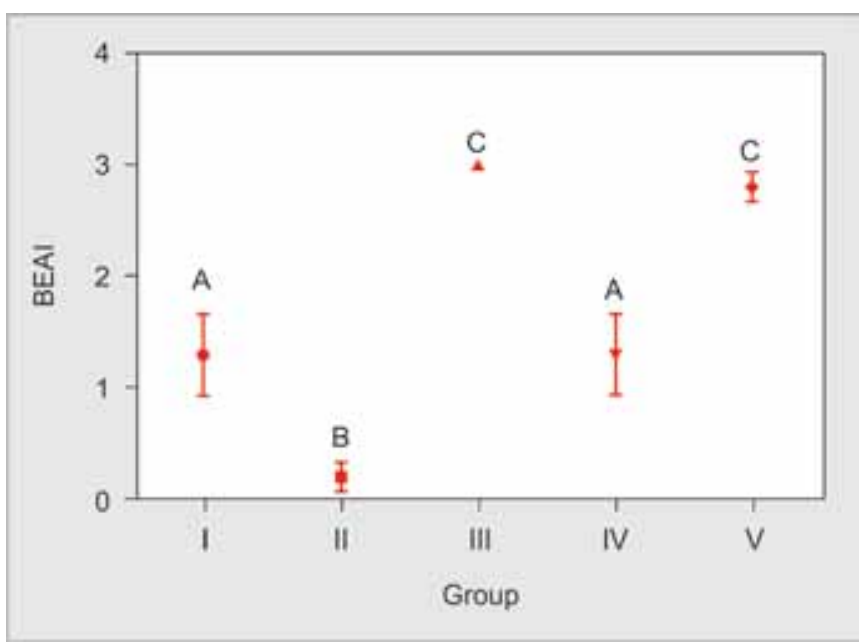

Graph 1: Results of BEAl comparison between groups by ANOVA and Tukey tests (mean and standard deviation). Groups with different letters had significant differences $(p<0.05)$

\begin{tabular}{lccccc}
\multicolumn{7}{c}{ Table 2: Frequency distribution of scores according to BEAI } \\
& Control (I) & EDTA (II) & Citric acid (III) & EDTA + Citric acid (IV) & Citric acid + EDTA (V) \\
& $n(\%)$ & $n(\%)$ & $n(\%)$ & $n(\%)$ & $n(\%)$ \\
\hline Score 0 & $2(20)$ & 0 & $10(100)$ & $2(20)$ & $8(80)$ \\
Score 1 & $2(20)$ & 0 & 0 & $2(20)$ & $2(20)$ \\
Score 2 & $3(30)$ & $2(20)$ & 0 & $3(30)$ & 0 \\
Score 3 & $3(30)$ & $8(80)$ & 0 & $3(30)$ & 0 \\
\hline Total & 10 & 10 & 10 & 10 & 10 \\
\hline
\end{tabular}


oral environment or covered by periodontal tissues but inside periodontal pockets. ${ }^{7}$ Tissue repair is possible after plaque and necrotic cementum removal of root surface by scaling and planning. ${ }^{8}$ On the other hand, scaling and root planning is unable to completely decontaminate root surface and results in production of a smear layer, ${ }^{9}$ which is formed by remnants of calculus, plaque and contaminated dental hard tissues (cement and dentin). ${ }^{10-12}$ The smear layer formed on root surface is comprised of very small particles of organic and inorganic material. These particles vary in size from less than $1 \mu \mathrm{m}$ to more than $15 \mu \mathrm{m}$, and the layer is in intimate contact with the tooth surface and only removed by applying a demineralizing solution. ${ }^{4}$ The interposition of this smear layer between the root surface and adjacent connective tissue, may act as a physical barrier for the development of a connective tissue attachment to the root surface. ${ }^{12,13}$

In 1984, Polson et $\mathrm{al}^{2}$ suggested that fibrin network linkage to root collagen fibers is necessary for the outcomes of a periodontal regenerative procedure. This way, Steinberg and Wiley ${ }^{14}$ studying the earliest events of clot formation on roots only planed or planed and conditioned by citric acid, suggested that surface thrombogenicity is very important for the adsorption of blood components. Also, the exposure of collagen fibers by the acid showed an improvement, at least initially, in clot organization. Moreover, a previous report showed that demineralized human root surface is more biocompatible to human periodontal ligament cells for early cell migration, attachment and orientation than the scaled and root planed diseased root surface alone. ${ }^{12}$

Citric acid causes the acidification of extracellular medium which induces cell death, also they suggest that $\mathrm{pH}$ elevation can prevent or diminish tissue damage. ${ }^{15}$ EDTA has been suggested as a chelating agent with neutral $\mathrm{pH}$ to avoid tissue damaging. ${ }^{16}$ This way, the aim of this study was to observe if the application of citric acid and EDTA could increase the amount of blood clot elements adhered to the root surface. Also, to verify if the use of EDTA after citric acid to neutralize its acidity and reduce the damage to surrounding tissues could be a treatment as effective as the isolated use of this acid for blood cells adhesion.

Previous reports have shown different explanations to citric acid effect in new attachment after periodontal therapy. Possible mechanisms could be related to a collagen union between exposed root surface fibrils and soft tissue collagen fibrils $;{ }^{17}$ binding of the two collagens by fibronectin in the early stages of wound repair; thus inhibiting the down growth of oral epithelium $;{ }^{18}$ enhanced fibroblast chemotaxis, migration and attachment; ${ }^{19}$ exposure of the root surface by removal of the smear layer ${ }^{2}$ and detoxification of pathologically altered root surfaces. ${ }^{20}$
Citric acid acts decreasing the $\mathrm{pH}$ causing surface demineralization with maintenance of collagen fibers integrity. ${ }^{4}$ We showed that citric acid can promote the most organized fibrin network and cells entrapment. In contrast, EDTA is a chelating agent which combines to calcium molecules from root surfaces removing them from the tooth surface. ${ }^{21}$

EDTA inhibited blood element adsorption and adhesion on dentin surface a result that can be attributed to the probably nonremoval of all gel of the root surface. Also, as a calcium chelators at neutral $\mathrm{pH}^{22}$ EDTA may have inhibited or retarded the coagulation events once calcium ions are essential in the coagulation cascade. Therefore, EDTA etching appeared to promote early cell and tissue colonization by providing a more biocompatible surface for cell and tissue attachment. ${ }^{13}$ In sum, collagen exposure benefits the initial steps of clot formation by activating the fibrin network formation. In addition, it induces platelet adhesion, aggregation, activation followed by degranulation of its cytoplasm granules, completing thrombus formation. ${ }^{1,6}$

The use of EDTA after citric acid as a neutralizing agent disturbed the good results obtained by the use of citric acid alone on clot organization. In vivo results should be carried out to verify whether this association can maintain connective tissue cells more viable to adhere on root surface.

\section{CONCLUSION}

Within the limitations of this study it was concluded that the application of citric acid and citric acid followed by EDTA on root surfaces affected by periodontal disease can improve clot organization while EDTA alone retard the coagulation cascade. Also, the use of EDTA after citric acid application as a way of neutralizing the acid does not disturb clot formation and organization in vitro.

\section{CLINICAL SIGNIFICANCE}

To demonstrate that citric acid use on root surfaces previously affected by periodontal disease may favor clot stabilization and may have a beneficial effect on surgical outcomes. Also, EDTA can be used to neutralize citric acid effects on periodontal cells.

\section{REFERENCES}

1. Dantas AA, Fontanari LA, Ishi Ede P, Leite FR, Zandim DL, Rached RS, Sampaio JE. Blood cells attachment after root conditioning and PRP application: an in vitro study. J Contemp Dent Pract 2012;13(3):332-338.

2. Polson AM, Frederick GT, Ladenheim S, Hanes PJ. The production of a root surface smear layer by instrumentation and its removal by citric acid. J Periodontol 1984;55(8):443-446. 
3. Trombelli L, Scabbia A, Zangari F, Griselli A, Wikesjo UM, Calura G. Effect of tetracycline $\mathrm{HCl}$ on periodontally-affected human root surfaces. J Periodontol 1995;66(8):685-691.

4. Cavassim R, Leite FR, Zandim DL, Dantas AA, Sampaio JE. Smear layer removal for collagen fiber exposure after citric acid conditionings. J Contemp Dent Pract 2010;11(6):E001-E008.

5. Leite FR, Moreira CS, Theodoro LH, Sampaio JE. Blood cell attachment to root surfaces treated with EDTA gel. Braz Oral Res 2005;19(2):88-92.

6. Leite FR, Sampaio JE, Zandim DL, Dantas AA, Leite ER, Leite AA. Influence of root-surface conditioning with acid and chelating agents on clot stabilization. Quintessence Int 2010;41(4):341-349.

7. Baker PJ, Rotch HA, Trombelli L, Wikesjo UM. An in vitro screening model to evaluate root conditioning protocols for periodontal regenerative procedures. J Periodontol 2000;71(7):1139-1143.

8. Bal B, Eren K, Balos K. Effects of various root surface treatments on initial clot formation: a scanning electron microscope study. J Nihon Univ Sch Dent 1990;32(4):281-293.

9. Baker DL, Stanley Pavlow SA, Wikesjo UM. Fibrin clot adhesion to dentin conditioned with protein constructs: an in vitro proofof-principle study. J Clin Periodontol 2005;32(6):561-566.

10. Fontanari LA, Pinto SC, Cavassim R, Spin-Neto R, Ishi Ede P, Sampaio JE. Influence of dental exposure to oral environment on smear layer removal and collagen exhibition after using different conditioning agents. Braz Dent J 2011;22(6):479-485.

11. Hanes PJ, Polson AM, Frederick GT. Initial wound healing attachments to demineralized dentin. J Periodontol 1988;59(3):176-183

12. Zaman KU, Sugaya T, Hongo O, Kato H. A study of attached and oriented human periodontal ligament cells to periodontally diseased cementum and dentin after demineralizing with neutral and low $\mathrm{pH}$ etching solution. J Periodontol 2000;71(7): 1094-1099.

13. Blomlof J, Lindskog S. Root surface texture and early cell and tissue colonization after different etching modalities. Eur J Oral Sci 1995;103(1):17-24.

14. Steinberg AD, Willey R. Scanning electron microscopy observations of initial clot formation on treated root surfaces. J Periodontol 1988;59(6):403-411.

15. Lan WC, Lan WH, Chan CP, Hsieh CC, Chang MC, Jeng JH. The effects of extracellular citric acid acidosis on the viability, cellular adhesion capacity and protein synthesis of cultured human gingival fibroblasts. Aust Dent J 1999;44(2):123-130.

16. Bergenholtz A, Babay N. Scanning electron microscopy of the root surface texture of extracted periodontally diseased teeth following various etching and chelating regimens. Int $\mathrm{J}$ Periodontics Restorative Dent 1998;18(2):171-179.
17. Heritier M. Effects of phosphoric acid on root dentin surface. A scanning and transmission electron microscopic study. J Periodontal Res 1984;19(2):168-176.

18. Karp W, Sodek J, Aubin JE, Melcher AH. A comparison of fibronectin and laminin binding to undemineralized and demineralized tooth root surfaces. J Periodontal Res 1986;21(1):30-38

19. Pitaru S, Melcher AH. Orientation of gingival fibroblasts and newly-synthesized collagen fibers in vitro. Resemblance to transseptal and dentogingival fibers. J Periodontal Res 1983;18(5):483-500.

20. Polson AM, Hanes PJ. Cell and fiber attachment to demineralized dentin. A comparison between normal and periodontitis-affected root surfaces. J Clin Periodontol 1987;14(6):357-365.

21. Sampaio JE, Campos FP, Pilatti GL, Theodoro LH, Leite FR. A scanning electron microscopy study of root surface smear layer removal after topical application of EDTA plus a detergent. J Appl Oral Sci 2005;13(3):247-252.

22. Blomlof J, Blomlof L, Lindskog S. Effect of different concentrations of EDTA on smear removal and collagen exposure in periodontitis-affected root surfaces. J Clin Periodontol 1997;24(8):534-537.

\section{ABOUT THE AUTHORS}

\section{Fabio Renato Manzolli Leite \\ (Corresponding Author)}

Adjunct Professor, Department of Semiology and Clinics, Federal University of Pelotas, Rio Grande do Sul, Brazil, Phone: 555332256741 e-mail: leite.fabio@gmail.com

\section{Gustavo Giacomelli Nascimento}

Graduate Student, Department of Restorative Dentistry, Federal University of Pelotas, Rio Grande do Sul, Brazil

\section{Elza Regina Manzolli Leite}

Professor, Department of Clinical Analysis, State University of São Paulo, São Paulo, Brazil

\section{Amauri Antiquera Leite}

Adjunct Professor, Department of Clinical Analysis, State University of São Paulo, São Paulo, Brazil

\section{José Eduardo Cezar Sampaio}

Adjunct Professor, Department of Diagnosis and Surgery, State University of São Paulo, São Paulo, Brazil 